\title{
OBSERVATIONS ON THE SPAWNING BEHAVIOUR OF SACCOGLOSSUS HORSTI BRAMBELL \& GOODHART, AND OF OTHER ENTEROPNEUSTA
}

\author{
By C. Burdon-Jones \\ Department of Zoology, University College of North Wales, Bangor
}

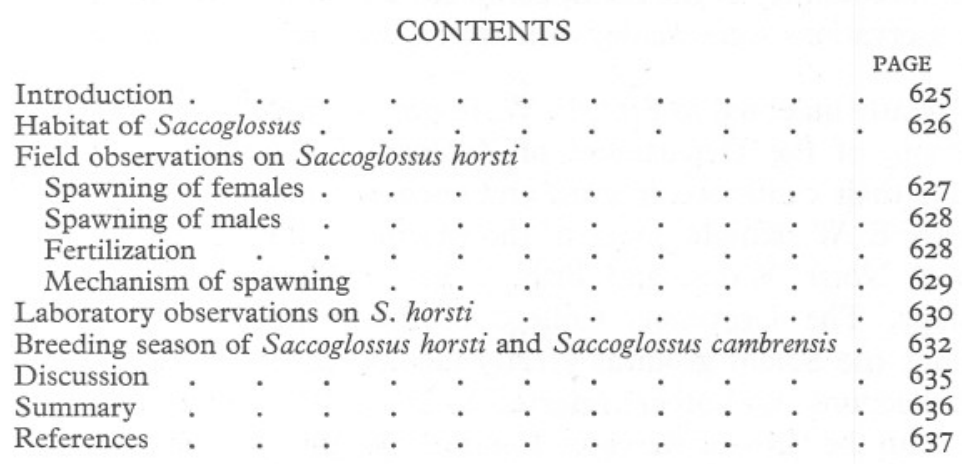

\section{INTRODUCTION}

A survey of the literature reveals few observations on the spawning behaviour of the Enteropneusta. Those existing are confined to descriptions of various continental species.

Bateson (I884, I886) suggested that Saccoglossus kowalevskyi Agassiz from Chesapeake Bay released its sperm and ova by a rupturing of the body wall, the former dehiscing as lobate spermatophoric masses. Ritter \& Davis (1904) studied $S$. pusillus Ritter at San Pedro, California, and stated that 'sperm is discharged in a delicate milky stream through the pores of the ripe genital lobes', and similarly the ova. They discovered eggs and embryos within a burrow, and concluded that that was their normal place of release and development. Davis (1908) collected all his material for a study of the embryology of $S$. pusillus from the burrows. Heider (1909) recorded a clump of eggs of Balanoglossus clavigerus Delle Chiaje amongst specimens received from Grado. Stiasny (1913) also worked on this species, and made observations on the method of spawning, fertilization and breeding season. A spawning male specimen of Glossobalanus marginatus was described by Meek (I922). This had been dredged from a depth of $52 \mathrm{fm}$. off the Farne Islands in the North Sea. Dawydoff (1928) described the egg masses of Glossobalanus minutus Kowalevsky at Naples. Laboratory records were made at Tortugas by Payne (1936) for Ptychodera bahamensis Spengel. Probably the most complete account of 
spawning as yet recorded, for any species, is that of Kirk (I937, I938), for Saccoglossus otagoensis Benham, found near Wellington, N.Z. This is a rockpool inhabitant, and has a comparatively specialized mode of spawning. During their study of $S$. pygmaeus, Hinrichs \& Jacobi (I938) noted some fertilized eggs in their aquaria, but they did not give many details.

The recent discovery of $S$. cambrensis in the Menai Straits (Brambell \& Cole, I939), and $S$. horsti in the Solent (Brambell \& Goodhart, I94I), provided an opportunity for a study of their development. The spawning behaviour will be dealt with here, and the development described in subsequent papers. The following account is, in the main, confined to $S$. horsti on which the majority of the observations were made, with appropriate references to other species.

I am greatly indebted to Prof. F. W. Rogers Brambell, F.R.S., and Dr T. B. Reynoldson, of the Department of Zoology, University College of North Wales, for their continued interest and encouragement throughout this work. Also to Dr E. W. Knight Jones of the Marine Biological Station, University College of North Wales, and Prof. J. E. G. Raymont of the Department of Zoology, The University College of Southampton, whose information concerning the Solent grounds greatly facilitated the collection of material. These collections, and others referred to in the text, were made possible by a grant from the Browne Research Fund of the Royal Society. The air and sea temperatures quoted for the Southampton area were very kindly provided by Lieut.-Commander D. H. Macmillan, R.N.R., Hydrographic Surveyor to the Southampton Harbour Board.

\section{Habitat of SACCOGLOSSUS}

$S$. horsti was originally described as occurring in deep grey mud, of a glutinous type, from just above low-water mark spring tides to a little way above lowwater mark neap tides. Subsequent exploration of the Solent area revealed a marked preference for areas of comparatively clean sand containing a smaller proportion of clay, silt, organic carbon and shell debris than was given in the original analysis. Such areas were invariably saturated, the water table lying above, or immediately below the surface of the sand. Shallow pools and streams of drainage water from neighbouring beds of Spartina townshendii Groves, and the upper reaches of the shore helped to maintain this saturated condition during the ebb tide. Regions were noted, however, where the water table was often 6 in. below the surface at the time of extreme low water. Surface casts and holes indicated that the number of specimens in these comparatively dry areas was less than in the others. A substrate of gravel, comparable to that so characteristic of the Saccoglossus cambrensis beds, was noted in many wellpopulated regions of the shore.

The animals live in reasonably well defined, irregularly coiled burrows, lined with mucus, and extending 4-8 in. below the surface. 


\section{Field ObSERVATIONS ON SACCOGLOSSUS HORSTI}

\section{Spawning of Females}

Collections were made on the Solent beds during all the workable tides of June I946, May I947, I948, I949 and May-June I950, but it was not until the last two years that any spawning was observed in the field.

The area worked during these years covered several acres of the shore, and surface casts averaging over 500 per $\mathrm{m}^{2}$ were common in the more densely populated parts. Observations were made throughout every tide during the period I2-I6 May I949, 28 May-2 June I950 inclusive. On both occasions ripe adults were extremely abundant and extraordinarily difficult to remove from their burrows without damaging them. Such pronounced ripeness had not been encountered in previous years. The condition was general.

Whilst making field notes on the evening ebb of I5 May 1949, the first indications of spawning were observed. Particles of detritus had been seen passing in a constant stream into a burrow, when the continuity of the flow was interrupted, became spasmodic, and was finally reversed. Detrital material which had just passed into the burrow was expelled. Almost immediately after this, a continuous flow of viscous, perfectly transparent mucus was seen to be exuding slowly from the burrow. Its refractive index was such as to make it almost invisible under the overlying water, but the movement of sand particles and detritus around its margin and settling on it from above indicated its shape and movement. When it first appeared this mucus was too viscous to be drawn up into a pipette of $\mathrm{I} .5 \mathrm{~mm}$. bore, but it became progressively less viscous after a period of exposure to the surrounding water. Light grey ovoid eggs then began to appear, embedded in a 'mucus cord', which coiled upon itself around the mouth of the burrow. The eggs were sparse at first, but soon the mucus cord was uniformly speckled with them. The cord was about $3 \mathrm{~mm}$. in diameter, the eggs about $0.25 \mathrm{~mm}$. and spaced roughly $0.5 \mathrm{~mm}$. apart. Occasionally they lay in rows 4 or 5 deep, but this arrangement was rapidly destroyed as the cord coiled upon itself and adjacent portions tended to fuse. The production of the egg mass usually went on steadily for 5-10 min., but sometimes it was rather erratic and more prolonged. The grey colour of the egg masses made them easily visible against the yellow of the sand. Spawning commenced about $30 \mathrm{~min}$. after the shore had been exposed by the receding tide. Within an hour the entire bed was 'splashed' with egg masses, each some 7-8 cm. ${ }^{2}$ in area. The number of specimens spawning at a time increased to a maximum during this period, and then gradually decreased. After $2 \mathrm{hr}$., the rate of production of new egg masses had declined considerably, and within $2 \frac{1}{2} \mathrm{hr}$. there was no evidence of any being formed. Although no accurate counts were possible in the field, it was estimated that each egg mass contained some 2500-3000 eggs. These were contained in cords some $15-20 \mathrm{~cm}$. long. Extension of the cord was, however, impossible, for the overlapping coils adhered tenaciously to 
each other immediately on contact, and the whole mass coalesced within minutes of its formation. The resultant mass resembled miniature frog's spawn in many respects, notably in its elastic and slippery nature, a property which made collection extremely difficult.

\section{Spawning of males}

Approximately $20 \mathrm{~min}$. after the first egg mass was seen, pale pink and milky white blotches began to appear amongst them. These were dense clouds of sperms issuing from the burrows of the males in much the same manner as that described for the eggs. The enveloping mucus was, however, less viscous, and in consequence the sperm clouds were slowly carried away and dispersed by the currents in the overlying water. These blotches, at first some $20-30 \mathrm{~cm} .^{2}$ in area, thus became thin streaks of pink or milky translucency, and extended for $30-40 \mathrm{~cm}$. from the burrow mouth before becoming so diffuse as to be invisible to the naked eye.

These observations are similar to those recently made by Newell (I948) on Arenicola marina L.

Although the area where this spawning took place had been carefully scrutinized for the entire period of its exposure during the morning and evening ebbs of the previous seven tides, and the subsequent one, the phenomenon was not repeated. Neither was there any evidence of it when the shore was examined during the ebb on the following morning.

\section{Fertilization}

Egg masses in the immediate vicinity of the sperm clouds erected their fertilization membranes rapidly, thereby increasing their diameter fourfold. Others, apparently upstream and beyond the visible range of dispersal of the sperms, also showed signs of fertilization, suggesting that it was not wholly. dependent on the currents in the overlying water.

The process of fertilization was accompanied by a gradual reduction in viscosity of the enveloping mucus as it was dissociated by the surrounding medium. Whereas there was evidence of disintegration of the egg mass prior to the fertilization of its constituents, there was no doubt that dissociation of the enveloping mucus took place rapidly once the fertilization membranes had been erected. The outermost eggs were fertilized first and soon detached themselves from the underlying ones. This process continued until the entire mass had been fertilized, and the eggs had been carried away by the currents in the overlying water, or remained in a loose cluster around the mouth of the burrow, to be subsequently dispersed by the incoming tide.

Partially fertilized egg masses, with the fertilized eggs as yet undetached, were observed in the direct flow of the sperms from the burrows. Such egg 
masses were pink or white with sperms, but the preponderance of male elements did not seem to affect the normal progress of fertilization and erection of membranes of the unfertilized eggs. Whereas the unfertilized eggs released by dissociation of the enveloping mucus either lay in crevices amongst the sand grains, or were slowly rolled away by the over-running stream, the more buoyant fertilized ones were carried away without any difficulty. This indicated that the specific gravity of the latter had been considerably reduced by the erection of their fertilization membranes. Crude artificial fertilizations carried out with freshly spawned eggs and sperm, in the field, indicated the existence of a maturation period comparable to that noted in the laboratory. The eggs were placed in about 500 c.c. of clean sea water in a collecting jar, and a few drops of sperm added. After gentle stirring they were allowed to stand undisturbed for $30 \mathrm{~min}$. When examined at the end of this period few of the eggs had been fertilized, but on further examination after an hour had elapsed the majority of the eggs had erected their fertilization membranes. These eggs remained in almost permanent suspension in the water when disturbed by stirring. The few remaining, unfertilized eggs settled rapidly. Although no control was possible under the circumstances, it seemed fairly certain that the eggs were impregnated by the sperms added, and not by any already present in the water.

\section{Mechanism of Spawning}

Since it was not possible to see the animals spawning, except for occasional glimpses of a proboscis at the burrow mouth, the behaviour of the animals during this period must be deduced from the way the genital products are forced out on to the surface.

The gradual outflow of detritus from the burrow prior to the appearance of mucus and, subsequently, of eggs or sperms, indicates a movement of the occupant towards the surface preparatory to spawning. The mucous glands secrete a larger quantity of mucus than usual. Probably the collar contributes a high proportion of the mucus, assisted by the large clusters of glandular cells in the genital and post-genital regions. When the release of the eggs and sperms has begun the animal is thought to retreat slowly to the lower regions of the burrow, continuing to produce large quantities of mucus, and spawning as it does so. After a short period the movement is reversed, and the animal now proceeds to force the mucus along with the enveloped eggs or sperm out of the burrow. This would explain the initial smooth outflow of the mucus cord from the burrow. Eggs and sperms were absent from the first few centimetres of this, possibly because the mucus comprising them was produced by the regions anterior to the gonads, viz. the proboscis, collar and the anterior branchial region of the trunk. The slow rhythmic flowing of the cord, referred to earlier, was probably due to the worm repeating the process. The even rather than patchy distribution of the sexual elements within the mucus indicates that 
they are released in an orderly manner and not cataclysmically. This suggests release through the genital pores, rather than by a rupturing of the body wall, a suggestion supported by the absence of evidence of disintegration in any spent specimens examined.

Complete discharge of the genital products does not take place, since the ovaries of adults always contain some large eggs. Specimens might thus spawn more than once in a season. Some were noted where the gonads were asymmetrically placed, an arrangement which might be due to one side discharging its products before the other. The remarkable synchronization between the times of release of the female and male elements indicated that this was an instance of induced spawning. Similar instances of induced spawning have been quoted, and described by Thorson (1946). Whereas the literature revealed the rule that ripe females of various invertebrates will not spawn unless induced to do so by the presence of the active sperm of their own species, the ripe females of Saccoglossus horsti spawned first, and seemed to induce the males to spawn. Other marine animals have been known to behave in a similar manner, e.g. Perinereis marionii (Herpin, I925) and Ostrea virginea (Galtsoff, I940), but they are comparatively few in number. Whether or not the inducement subsequently became mutual, as noted by Coe (1947) for Tivela stultorum, was not evident, but the result was an 'epidemic' spawning such as that described by Hargitt (I9IO) for Hydroides dianthus, and those quoted by Thorson (I950) for other polychaetes and certain molluscs. The chances of all the eggs spawned being fertilized were thus greatly increased because they were present simultaneously with enormous quantities of sperm in a comparatively small volume of water. Unfertilized eggs were very scarce at the onset of the flood, so that the mode of spawning was seemingly an extremely efficient one.

\section{LABORATORY OBSERVATIONS ON SACCOGLOSSUS HORSTI}

Over the past 4 years some 200 mature specimens of $S$. horsti, along with a considerable quantity of their native mud and sand, were transported to Bangor and maintained in a healthy condition for periods of varying duration up to 6 months. This material was required for embryological purposes, so that observations on spawning were incidental. Nanoplankton cultures were provided as food. The aquaria were aerated.

After an acclimatization period of $\mathrm{I}$ or 2 days, the specimens settled down in burrows which they frequently made along the glass sides of the aquaria. Observation of their behaviour was thus greatly facilitated.

The surface of the mud, particularly in the immediate vicinity of burrows known to be occupied by females, and the interiors of any burrows alongside the walls of the aquaria, were carefully scrutinized at regular intervals daily, for the first 6 weeks after the collection and at less frequent intervals afterwards. Since the aquaria were situated in reduced light, well away from any 
sunshine, eggs were difficult to see against the mud and silt which invariably settled in the aquaria. Some illumination was essential, and a small spot-light electric torch proved extremely useful. The beam from this could be directed in through the sides of the aquaria, and along the surface of the mud. Egg clusters illuminated in this way could be seen clearly against the dark substrate. It was also useful for the examination of the remoter regions of the burrows.

Although the author was never fortunate enough to observe any spawning within the 'open' burrows along the walls of the aquaria, several instances of spawn issuing from the burrows were recorded. Although these were in the main exactly as observed in the field, occasions were noted when fertilized and unfertilized eggs were seen to be exuding from the burrows. They flowed out in a manner which suggested that the female was pushing them, for her proboscis appeared at the mouth of the burrow from time to time, as more and more eggs were forced out on to the surface. The tip of the proboscis was observed once, under similar circumstances, in the field.

The enveloping mucus of the egg masses seemed to dissociate more rapidly in the aquaria. Several times eggs were found lying loose on the surface, with no evidence of any mucus around them. Some $50 \%$ of these were fertilized when discovered. This suggested that the dissociation of the mucus was not due to the action of the sperm alone, but to other factors, possibly the $\mathrm{pH}$ of the surrounding medium.

Sperm clouds observed in the laboratory were dispersed by the aeration currents and were similar to those seen in the field. Microscopic examination of a sample taken from one of these clouds showed that the sperms were solitary, and very active. Isolated samples of naturally and artificially released sperms maintained their vigour for several hours. One sample accidentally raised to $29^{\circ} \mathrm{C}$. still contained numerous active sperms.

Fertilizations were carried out with naturally spawned eggs, and artificially as well as naturally released sperms. Freshly spawned eggs did not erect their membranes, after the addition of sperms, as rapidly as those which had been spawned for some time. At $\mathrm{I} 6-\mathrm{I} 7^{\circ} \mathrm{C}$. a maturation period of $30 \mathrm{~min}$. to I hr. ensued before impregnation could be effected. The eggs remained fertilizable for periods varying from 6 to Io hr. Mature eggs, released some 2-3 hr. prior to the addition of sperms, erected their fertilization membranes within IO-I5 min. On one occasion a few drops of a sperm suspension were injected into the burrows of several ripe females, and small clusters of eggs were observed around the mouths of many of these burrows the following morning, some ro hr. later. No further experiments of this nature were carried out, but this single observation suggested that the females were induced to spawn by the presence of sperm. 


\section{BREeding SEASON of SACCOGLOSSUS HORSTI AND SACCOGLOSSUS CAMBRENSIS}

Collections were made in the Solent area during the periods I4. vi. 46-I6. vi. 46; 20. v. 47-23. v. $47 ; 7$. v. 48-I2. v. 48 and II. v. 49-I6. v. 49. Some 400 specimens were examined in all. Collections could not be made earlier than May, but from the general condition of the gonads, and the paucity of spent or partially spent specimens, it was concluded that the first three collections had been made prior to the main spawning crisis for those years, and during the first main crisis for the latter. This conclusion is borne out by subsequent records of spawning in the aquaria, for apart from those stimulated to spawn by the 'shock' of collection, the majority spawned during the following 4-6 weeks. Whilst recognizing that the artificial conditions under which the animals were maintained may influence their behaviour, it is felt that the records of spawning, thus obtained, give some indication of the duration of the breeding season and the conditions under which it probably takes place.

Spawning was first recorded in the laboratory by Dr E. W. Knight Jones on 20. v. 46 , and subsequently by the author from I 7. vi. 46 to I 5. vii. $46 ; 25$. iv. 47 to 3 O. v. 47 ; I8. v. 48 to I. vi. 48 , and on three occasions I5. v. 49 , I. vi. 50 and $2 . v i .50$ in the field. These records were mainly of one, often two, rarely three specimens spawning in any one day. There was never any indication of a concerted effort comparable to the field records.

Temperature records show that specimens will spawn over a fairly wide range, from 13.5 to $21.0^{\circ} \mathrm{C}$. A temperature rise prolonged over 2 or 3 days invariably resulted in some specimens spawning. Some $60 \%$ of the records were made at $\mathrm{I} 6-\mathrm{I} 7^{\circ} \mathrm{C}$., $30 \%$ below, and the remainder above. Many eggs were spawned at comparatively low temperatures ( $14.5^{\circ} \mathrm{C}$.) and failed to develop beyond the 3 rd or 4 th cleavage. Others spawned at higher temperatures $\left(20^{\circ} \mathrm{C}\right.$.) suffered the same fate, but those produced between $I 6$ and $I 7^{\circ} \mathrm{C}$. developed normally and the larvae were successfully reared until they had several pairs of gill-apertures.

The occurrence of several spent specimens amongst those examined from the Solent collections of June 1946 indicated that some spawning had already taken place, probably during the previous spring tides. Air and sea temperatures in the area for this period were suitable, and rose from II $\cdot$ I to $15^{\circ} 6^{\circ} \mathrm{C}$. during the period 27. v. 46-30. v. 46, whilst the main Southampton water was c. $14.4^{\circ} \mathrm{C}$. Inshore temperatures would have been proportionately higher, particularly in the sheltered regions, and thus ideal for spawning.

In the collections of May I947 a fairly high proportion of immature specimens was noted, and the impression gained was that spawning had not yet commenced for that season, but it did so in the laboratory some 4-5 days later.

Specimens collected during May 1948 were extremely ripe, and very difficult to handle without causing injury. Several hot days followed their 
transfer to the laboratory, and spawning commenced on the I8th, a week after they had been collected. The extreme ripeness of the numerous specimens observed in the field indicated the imminence of a spawning crisis, possibly the first of the season, for spent specimens were very rare. Air temperatures for the period $7 . \mathrm{V} .4^{8}-\mathrm{II}$. V. 48 rose from II I to $\mathrm{I} 5 \cdot 6^{\circ} \mathrm{C}$., the sea temperature rising from $\mathrm{I} 2.2$ to $\mathrm{I} 4.4^{\circ} \mathrm{C}$, , but the air temperature dropped to $\mathrm{I} 3.3^{\circ} \mathrm{C}$. the next day, and subsequently to $10^{\circ} \mathrm{C}$. for the 13 th and most of the I4th. This might well have delayed the spawning until the next temperature rise took place during the afternoon of the 14 th, when it rose to $16.7^{\circ} \mathrm{C}$., and then to $20^{\circ} \mathrm{C}$. on the 15 th. Temperatures remained at about this level throughout the next few days, but since the tides had lapsed into neaps during this period it is thought that the full effect of the rise would not be felt, and that in all probability spawning did not start until the onset of the next series of spring tides when there were several warm days and maximum air temperatures varied from i9 to $22^{\circ} \mathrm{C}$.

At the time of the mass spawning in the Solent (15. v. 49) the temperature of the shallow surface water in the inlet during the ebb was $17.5^{\circ} \mathrm{C}$., and that of the sand varied from $\mathrm{I} 5$ to $16^{\circ} \mathrm{C}$. according to the degree of exposure to the sun. The temperature at a depth of 6 in. in the sand was some $2^{\circ} \mathrm{C}$. below that recorded at the surface. The sea temperature ${ }^{1}$ was at $12 \cdot 8^{\circ} \mathrm{C}$. on that day, having risen steadily from $\mathrm{II} \cdot 6^{\circ} \mathrm{C}$. recorded on 8 . v. 49 , whilst the air temperature had risen with slight fluctuations from $7 \cdot 8^{\circ} \mathrm{C}$. at I8.00 hr. on II. v. 49 to $\mathrm{I} 4.4^{\circ} \mathrm{C}$. at $\mathrm{I} 2.00 \mathrm{hr}$. and to $\mathrm{I} 6.7^{\circ} \mathrm{C}$. at $\mathrm{I} 8.00 \mathrm{hr}$. on I 5 . v. 49 . The phenomenon was repeated on two successive occasions during the spring tides of June, I950. The beds had been examined during the ebb tides of the previous four days, but it was not until the afternoon ebb of Ist June that spawning commenced. In every respect the progress of events was comparable to those observed in 1949. Spawning began some $30 \mathrm{~min}$. after the tide had receded, and was mainly confined to those areas of the beds which were covered by shallow pools. The temperature of the water in these pools was $2 \mathrm{I}^{\circ} \mathrm{C}$., and that of the underlying sand was $17^{\circ} \mathrm{C}$. at a depth of 6 in. below the surface. Although several egg masses were observed within a few minutes of the discovery of the first it was some time before the first sperm cloud was seen. The intensity of spawning was greater than that experienced previously, and an arbitrarily chosen square metre of the shore contained I25 casts, 2I egg masses and 5 sperm clouds. The production of egg masses reached its climax some $\mathrm{I} \frac{1}{2}-2$ hrs. after the tide had ebbed, whilst the production of sperm clouds continued vigorously until the flood had commenced, when it abated markedly. Examination of the area at 6 a.m. the following morning failed to reveal any traces of the spawning. The water in the surface pools at this hour had fallen to $17 \cdot 2^{\circ} \mathrm{C}$., but that of the sand remained at $17 \cdot 0^{\circ} \mathrm{C}$. During the afternoon

${ }^{1}$ The sea temperatures quoted are for the main Southampton Water, unless otherwise stated. 
ebb of this day the water temperature rose to $21.5^{\circ} \mathrm{C}$. and that of the sand to I $7.5^{\circ} \mathrm{C}$., and spawning commenced as on the previous day.

Since similar weather and tidal conditions prevailed for the succeeding two days it is likely that the intermittent spawning would continue until the tides lapsed into neaps. A temperature rise seems to have played a major part in initiating the mass spawning observed on these three occasions, for they all occurred after the shore had been subjected to hours of fairly intense sunshine over a period of several days. Orton (I920) and Thorson (1946, I950) have shown that temperature influences the spawning of numerous marine invertebrates. Korringa (1947) cites several examples where tidal influences also play an important part. It would seem that both factors are probably concerned in the spawning of $S$. horsti.

Specimens of $S$. cambrensis have been examined at all times of the year, and whereas they were apparently always ripe, there was very little evidence of any spawning. A close inspection of the more densely populated areas in the Menai Straits made during the spring tides of June and July I949, yielded several empty egg cases. These were discovered in the sand around the mouths of burrows. They were very similar to those of $S$. horsti, but in the absence of any embryos the identification must remain uncertain. One egg contained a cream-coloured ovoid embryo which was densely ciliated, and very like the late gastrula stage of $S$. horsti. It rapidly disintegrated in the laboratory, so that little else can be said about it. Tow-nettings with a no. I5 bolting silk net were made over the surface of the sand just prior to its exposure by the receding tide. These yielded several more empty egg cases, all of the same size and appearance. Since these were discovered within a short period of the mass spawning in the Solent, and under comparable weather conditions, it is possible that a spawning had already taken place in the Menai Straits and that the egg cases were the remnants of eggs which had hatched either in the burrows and were subsequently expelled, or in amongst the sand grains on the surface. Some fifty specimens of a Saccoglossus species (Burdon-Jones, I950b) examined in the Sound of Mull, during the spring tides of August 1948, revealed that ripe females and, to a lesser degree, ripe males, were comparatively rare. Numerous specimens were difficult to sex because they were either spent, or immature. The impression gained was that the main spawning, for that year, had already taken place. Numerous adult specimens of a species of Protoglossus (BurdonJones, 1950a) were examined during August, September and October 1949, and although mature specimens of both sexes were collected, they were very much in the minority, the paucity being most pronounced amongst the females. These observations, once more, suggest a breeding season at some time during the preceding few months, viz. May to July.

It would seem that the main spawning season for the British species of the Harrimanidae is mainly during the months of May to July. Mass spawning comparable to that described for Saccoglossus horsti is likely to be common to them all and to take place under similar climatic and tidal conditions. 


\section{Discussion}

In the light of this new information, it remains for us to examine what is known of the spawning behaviour in the other species of Enteropneusta.

Bateson (1884) suggested that in Saccoglossus kowalevskyi the eggs and sperms, the latter aggregated in lobate masses, were released by a rupturing of the body wall. Spengel (1893) pointed out the improbability of this, basing his arguments on the mode of maturation of the gonads. His comments were borne out by the discovery of large genital apertures in mature Glossobalanus ruficollis, which Willey (I899) noted would enable eggs to be released without any difficulty. There was no evidence of rupturing in Saccoglossus horsti, or any evidence of increased mortality amongst spawning specimens in the laboratory or in the field. Rupturing and spermatophoric masses have been observed only in one other species, viz. S. otagoensis (Kirk, I937, 1938), but this is a rock-pool inhabitant, and has a specialized mode of spawning in keeping with its habitat.

For $S$. pusillus Ritter \& Davis (I904) recorded mature specimens in August, and suggested that the breeding season extended over at least 4 months. Davis (I908) discovered that the main breeding season was in January and February. The genital products were released through the genital apertures as in $S$. horsti, but the eggs were discovered closely packed and somewhat flattened, and adhering to the walls of inhabited burrows. Their appearance and situation suggests that they were not expelled with the main clutch, but had been pressed into the mucus lining of the burrow whilst spawning was taking place. In this position they could be fertilized by sperms carried into the burrow by the aerating currents of the animal within it, and thus aerated and protected they would develop. In the light of the observations on $S$. horst $i$ however, these eggs might be regarded as a remnant of the main egg mass which had been expelled from the burrow and probably washed away by the tide, or camouflaged by silting. Since the habitat was a muddy one, this could easily have occurred and, in consequence, the eggs might well have been overlooked.

Stiasny (I9I3) made comparable observations on Balanoglossus clavigerus. It is significant that he noticed eggs were easily overlooked within the burrows because their colour closely resembled that of the sand. Under such circumstances it is probable that they might also be overlooked if lying on the surface.

On this interpretation, spawning of Saccoglossus pusillus may be comparable to that noted in S. horsti, and so also might that of Balanoglossus clavigerus, for Heider (1909) recording observations made on specimens in the laboratory noted:

Am I2. Juni, um $6 \mathrm{Uhr}$ nachmittags fand sich an der Mündung einer solchen Wohnröhre ein schleimiger Laichklumpen von etwa Nussgrösse. Der Schleim, in welchem Hunderte von Eiern eingeschlossen waren, ist ungemein zerfliesslich, und nachdem der Laich herauspipettiert war und das Gefäss in welchem er sich nun befand, einigem Schütteln ausgesetzt war, löste er sich scheinbar vollständig auf. 
Because the observations were made on specimens in an aquarium, van der Horst (1927-39) queried the probability of such egg masses occurring in the field. Nevertheless, they occurred in Saccoglossus horsti, both in the laboratory and on the shore, so that we must regard Heider's observations as being indicative of a similar occurrence in Balanoglossus clavigerus, although this was never confirmed by Stiasny.

Kowalevsky (I866) made the supposition that, 'Es ist wahrscheinlich, dass der Balanoglossus Eierschnüre legt, in der Art, wie es die meisten Nemertinen und viele Anneliden thun', but Agassiz (I872) failed to find any whilst working on Saccoglossus kowalevskyi. Subsequently, this theory was strongly deprecated by Spengel (1893) on the grounds that the gross morphology of the gonads would make it impossible. The observations on $S$. horsti tend to invalidate this statement, for when first expelled from the burrow the eggs of this species are in a cord which coils on itself and rapidly fuses into a single mass. The existence of such cords is not necessarily universal, but they have also been described in Glossobalanus minutus (Dawydoff, I928). The persistence of the cord undoubtedly depends on the conditions under which it is expelled from the burrow. Certain specific variations might well occur.

From the above observations and those of Russell (1925) and others, on the seasonal occurrence of enteropneust larvae in the English Channel, North Sea and various parts of the world, and the large numbers of Tornaria larvae of the same size that are often found together, it might be concluded that an 'epidemic' spawning comparable to that described for Saccoglossus horsti, and initiated and perpetuated in a similar manner, is common to all the littoral and possibly some sub-littoral species of the families Ptychoderidae and Harrimanidae.

\section{SUMMARY}

The genital products of Saccoglossus horsti are discharged within the burrows and expelled after the tide has ebbed. They are not retained in the burrows for any length of time.

Fertilization occurs mainly in the overlying surface water, or during the flood.

An 'epidemic' spawning was observed on three occasions in the field.

A rise of temperature to about $16^{\circ} \mathrm{C}$, is regarded as the essential factor primarily responsible for initiating the spawning.

The females were observed to spawn before the males. Some reciprocal inducement might have occurred.

The breeding season in the Solent area is mainly confined to the months of May, June and July, and is seemingly dependent on climatic and tidal conditions during these months.

The spawning behaviour of other species of the Enteropneusta is discussed. 


\section{REFERENCES}

Agassiz, A., I872. The history of Balanoglossus and Tornaria. Mem. Amer. Acad. Arts Sci., Vol. Ix, pp. 421-36.

BAteson, W., I884. The early stages in the development of Balanoglossus (sp. incert.). Quart. Fourn. Micr. Sci., Vol. xcIv, pp. 208-36.

- 1886. Continued account of the later stages in the development of Balanoglossus kowalevskii, and of the morphology of the Enteropneusta. Quart. Fourn. Micr. Sci., Vol. CII, pp. 5II-33.

Brambell, F. W. Rogers \& Cole, H. A., I939. Saccoglossus cambrensis, sp.n., an enteropneust occurring in Wales. Proc. Zool. Soc. Lond., B, Vol. I09, pp. 21 I-36.

Brambell, F. W. Rogers \& Goodhart, C. B., I94I. Saccoglossus horsti sp. n., an enteropneust occurring in the Solent. Fourn. Mar. Biol. Assoc., Vol. xxv, pp. 283301.

Burdon-Jones, C., I950 $a$. An enteropneust genus new to the British Isles. Nature, Vol. I65, p. 327.

I950b. Records of British Enteropneusta. Nature, Vol. I65, pp. 636-7.

CoE, W. R., I947. Nutrition, growth and sexuality in the pismo clam (Tivela stultorum). Fourn. Exp. Zool., Vol. 104, pp. I-24.

Davis, B. M., I908. The early life-history of Dolichoglossus pusillus Ritter. Univ. Calif. Publ. Zool., Vol. 4, pp. 187-226.

DAwydoff, C., I928. Quelques observations sur le développement des entéropneustes. C.R. Acad. Sci., Paris, T. 186, pp. 173-5.

GALTSOFF, P. S., I940. Physiology of reproduction of Ostrea virginica. III. Stimulation of spawning in the male oyster. Biol. Bull. Woods Hole, Vol. LxxviII, pp. II7-35.

HARgitt, C. W., I9Io. Observations on the spawning habits of Hydroides dianthus. Amer. Nat., Vol. 44, pp. 376-8, New York.

HeIder, K., I909. Zur Entwicklung von Balanoglossus clavigerus Delle Chiaje. Zool. Anz., Bd. 34, 695-704.

HeRPIN, R., I925. Recherches biologiques sur la reproduction et le développement de quelques annélides polychétes. Bull. Soc. Sci. Nat. de l'Ouest de la France, Ser. 4, T. $5,250 \mathrm{pp}$.

HINRICHS \& JACOBI, L., 1938. Saccoglossus pygmaeus, eine neue Enteropneustenart aus der südlichen Nordsee. Zool. Anz., Bd. I21, pp. 25-32.

Horst, C. F. vAN DER, 1927-39. Hemichordata. Bronn's Klassen u. Ordn. Tierrichs., Bd. Iv, Abt. 4, Buch 2, Tiel 2, 737 pp.

KIRK, H. B., I937. The embryology of Dolichoglossus otagoensis Benham (Abstract). Rep. Aust. Assoc. Adv. Sci., Vol. 23, 137-8.

- I938. Notes on the breeding habits and the early development of Dolichoglossus otagoensis Benham. Trans. Proc. Roy. Soc. N.Z., Vol. 68, pp. 49-50.

KorRINGA, P., I947. Relations between the moon and periodicity in the breeding of marine animals. Ecol. Monographs, Vol. 17, pp. 347-81.

Kowalevsky, A., I866. Anatomie des Balanoglossus Delle Chiaje. Mem. Acad. Imp. Sci. St. Petersb., Sér. VII, T.X. No. 3, I8 pp.

MeEk, A., I922. Glossobalanus marginatus, a new species of Enteropneusta from the North Sea. Quart. Fourn. Micr. Sci., Vol. 66, pp. 579-94.

Newell, G. E., I948. A contribution to our knowledge of the life history of Arenicola marina L. Fourn. Mar. Biol. Assoc., Vol. xxvII, pp. 554-80.

Orton, J. H., I920. Sea-temperature, breeding and distribution in marine animals. fourn. Mar. Biol. Assoc., Vol. xII, pp. 339-66. 
Payne, F., 1936. Early development of Ptychodera bahamensis. Pap. Tortugas. Lab., Vol. xxxI, (no. IV,) pp. 73-6.

Ritter, W. E., \& Davis, B. M., I904. Studies on the ecology, morphology and speciology of the young of some Enteropneusta of western N. America. Univ. Calif. Publ. Zool., Vol. I, pp. 171-210.

RUSSELL, F. S., I925. The vertical distribution of marine macroplankton. An observation on diurnal changes. Fourn. Mar. Biol. Assoc., Vol. xIII, pp. 769-809.

Spengel, J. W., I893. Die Enteropneusten des Golfes von Neapel. Fauna u Flora Neapel, Vol. xviII, 757 pp.

Stiasny, G., I9r3. Studien über die Entwicklung von Balanoglossus clavigerus, D.Ch. Zool. Anz., Bd. 42, pp. 487-500.

Thorson, G., I946. Reproduction and larval development of Danish marine bottom invertebrates, with special reference to the planktonic larvae in the Sound (Øresund). Medd. Komm. Danmarks Fisk. Havund., Ser. Plankton., Bd. 4, Nr. I, $523 \mathrm{pp}$.

I950. Reproductive and larval ecology of marine bottom invertebrates. Biol. Rev., Vol. 25, pp. I-45.

Willey, A., I899. Enteropneusta from the South Pacific, with notes on the West Indian species. Willey's Zoological Results, Pt. III, pp. 223-334. 